\title{
Innegligible musculoskeletal disorders caused by zoledronic acid in adjuvant breast cancer treatment: a meta-analysis
}

\author{
Wen-Bin Zhou', Peng-Ling Zhang ${ }^{2}$, Xiao-An Liu', Tao Yang ${ }^{3}$ and Wei He ${ }^{3 *}$
}

\begin{abstract}
Background: Zoledronic acid (ZOL) is widely used for preventing bone loss in early breast cancer patients. However, the adverse effects caused by ZOL itself should not be neglected. Musculoskeletal disorders were common after ZOL administration and distressing to the patients. Up to now, no precise estimation of musculoskeletal disorders has been made.
\end{abstract}

Methods: Relevant randomized clinical trials were selected by searching the electronic database PubMed, and a meta-analysis was conducted.

Results: Four trials reported musculoskeletal disorders of ZOL treatment versus no ZOL, including 2684 patients treated with ZOL and 2712 patients without ZOL treatment. Compared to patients without ZOL treatment, patients treated with ZOL had a significantly higher risk of arthralgia (risk ratio (RR): 1.162, 95\% confidence interval (Cl): $1.096-1.232, P=0.466$ for heterogeneity) and bone pain (RR: $1.257,95 \% \mathrm{Cl}: 1.149-1.376, P=0.193$ for heterogeneity). Three clinical trials reported the complications of upfront versus delayed ZOL treatment, including 1091 patients with upfront ZOL and 1110 patients with delayed ZOL. The rate of bone pain in upfront group (119/ 824) was significantly higher than that in delayed group (74/836) (RR: $1.284,95 \%$ Cl: $1.135-1.453, P=0.460$ for heterogeneity).

Conclusions: Our meta-analysis suggested that treatment with ZOL was significantly associated to the occurrence of arthralgia and bone pain. Moreover, higher rate of bone pain was observed in patients treated with upfront ZOL compared with delayed ZOL treatment. More attentions should be paid to patients treated with ZOL, especially for immediate ZOL. For patients with low risk of osteoporosis, immediate ZOL may be not needed due to additional musculoskeletal disorders and little benefit. Or it can be stopped after the occurrence of these adverse events.

Keywords: zoledronic acid, musculoskeletal disorders, breast cancer, meta-analysis

\section{Introduction}

More patients with early breast cancer have been diagnosed with the development of screening techniques [1]. Following adjuvant chemotherapy and endocrine therapy can significantly improve disease-free survival (DFS) and overall survival (OS) in early breast cancer patients [2-4]. However, both adjuvant chemotherapy and endocrine therapy cause bone loss to these patients. Patients

\footnotetext{
* Correspondence: hewei1007@sina.cn

${ }^{3}$ Department of Endocrinology and Metabolism, The First Affiliated Hospital with Nanjing Medical University, 300 Guangzhou Road, 210029 Nanjing, China

Full list of author information is available at the end of the article
}

with amenorrhea after chemotherapy [5,6] and postmenopausal patients receiving aromatase inhibitors (AIs) are at high risk of bone loss [3,4,7-9].

Zoledronic acid (ZOL) can prevent bone loss in early breast cancer patients [10]. Furthermore, ZOL also has antitumor and antimetastatic properties. The previous meta-analysis [11] suggested that the use of ZOL was associated with a statistically significant lower risk for disease recurrence. In addition, ZOL has several potential advantages compared to the oral bisphosphonates, including good bioavailability, gastrointestinal tolerance, and adequate compliance [12]. Thus, less adverse effects, such as gastrointestinal disorders and vascular disorders,

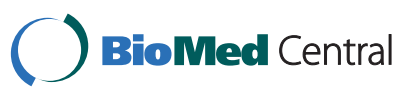


were caused by ZOL [12]. However, the adverse effects caused by ZOL itself should not be neglected. Osteonecrosis of the jaw, an uncommon serious side effect caused by ZOL, has been paid close attention. Previous study [13] showed that osteonecrosis of the jaw occurred in only about $0.33 \%$ of patients treated with ZOL. Musculoskeletal disorders were common after $\mathrm{ZOL}$ administration and distressing to the patients. Up to now, no precise estimation of musculoskeletal disorders has been made. Previous randomized clinical trials [14-17] showed that musculoskeletal disorders occurred in more than $20 \%$ patients treated with $\mathrm{ZOL}$ and in more than $10 \%$ patients without ZOL treatment. Furthermore, some randomized trials $[12,18,19]$ were conducted to evaluate the efficacy of upfront ZOL versus delayed ZOL in preventing bone loss. The musculoskeletal disorders reported by these trials were discordant.

The UK Expert Group [20] suggested that bisphosphonates should be administrated to patients with high risk of osteoporosis. However, patients with low risk of osteoporosis might benefit little from ZOL treatment. When ZOL was considered to be administrated to patients, the benefit and adverse effects should be well balanced. We performed this meta-analysis to give a precise estimation of the musculoskeletal disorders of $\mathrm{ZOL}$ versus no $\mathrm{ZOL}$ and upfront $\mathrm{ZOL}$ versus delayed $\mathrm{ZOL}$ in adjuvant breast cancer treatment.

\section{Methods}

\section{Search strategy}

The present study was conducted as described previously [21-23]. Relevant studies were selected by searching the electronic database PubMed (updated on May 1, 2011), using the following terms: early or adjuvant, breast cancer or breast neoplasm, zoledronic acid or bisphosphonates. Two investigators (Zhou WB and Liu XA) independently evaluated titles and abstracts of the identified papers. References in identified articles and reviews were also reviewed for possible inclusion. Only published randomized clinical trials in English language were included in our study. Randomized clinical trials were included if they met the following criteria: (1) ZOL used in breast cancer patients in adjuvant setting; (2) ZOL used with a control group receiving no treatment or placebo, or upfront ZOL (receiving ZOL immediately after randomization) versus delayed ZOL (receiving ZOL only if $T$-score fell below -2.0, after a nontraumatic clinical fracture, or if an asymptomatic fracture); (3) enough published data for estimated a risk ratio (RR) with $95 \%$ confidence interval (CI). In addition, to avoid duplication of information, only the report with longest follow-up was included for calculations when multiple reports pertained to overlapping groups of patients.

\section{Data extraction}

The data of musculoskeletal disorders, including arthralgia, bone pain and muscle pain, were carefully extracted from all the eligible randomized trials independently by two investigators (Zhou WB and Liu XA). The following variables were extracted from each study: first author's name, the name of each trial, publication year, the median follow-up time, the number of total patients in every group, and the number of patients with musculoskeletal disorders in every group. All the data were reached consensus after discussion.

\section{Statistical analysis}

Crude RRs with 95\% CI were used to assess the musculoskeletal disorders risk of ZOL. The between-study heterogeneity was tested with $Q$ statistics (significant differences indicated by $P<0.10)$ [24]. The fixed-effects model (the Mantel-Haenszel method) was used when between-study was absent [25]. Otherwise, the randomeffects model (the DerSimonian and Laird method) was selected [26]. Funnel plots and Egger's linear regression were used to test the publication bias and a $P$ value less than 0.05 was considered significant. All analyses were performed using the software Stata version 11.0 (Stata Corporation, College Station, TX, USA).

\section{Results}

\section{Eligible studies}

Ten randomized clinical trials, in which ZOL was used in adjuvant setting, were identified. Of these ten studies, the detail data of musculoskeletal disorders were not reported in three studies [27-29]. In all, seven studies [12,14-19] were eligible in this meta-analysis. Table 1 presented the characteristics of the seven trials. Of these seven studies, four studies [14-17] reported musculoskeletal disorders of ZOL versus placebo or no treatment, including 2684 patients treated with ZOL and 2712 patients treated with placebo or no treatment. Three studies $[12,18,19]$ reported the complications of upfront versus delayed ZOL, including 1091 patients with upfront ZOL and 1110 patients with delayed ZOL.

\section{ZOL versus no ZOL}

Table 2 showed the main results of this meta-analysis. Arthralgia occurred in about $23.9 \%-68 \%$ patients treated with ZOL and $12.5 \%-60.4 \%$ patients without ZOL treatment. Compared to patients without ZOL treatment, patients treated with ZOL had a significantly higher risk of arthralgia (RR: $1.162,95 \%$ CI: 1.096-1.232, $P=0.466$ for heterogeneity) (Figure 1). Bone pain occurred in about $35.3 \%-40 \%$ patients treated with $\mathrm{ZOL}$ and in $24.6 \%-41.5 \%$ patients without ZOL treatment. Similarly, a significantly higher risk of bone pain was observed in patients with ZOL treatment (RR: 1.257, 95\% CI: 1.149 - 
Table 1 Characteristics of eligible trials

\begin{tabular}{|c|c|c|c|c|c|c|}
\hline $\begin{array}{l}\text { Author } \\
\text { (Study) }\end{array}$ & Year & Intervention & Dosage of treatment & $\begin{array}{l}\text { Duration } \\
\text { (yr) }\end{array}$ & $\begin{array}{l}\text { Number of } \\
\text { patients }\end{array}$ & $\begin{array}{l}\text { Follow-up } \\
\text { (mo) }\end{array}$ \\
\hline $\begin{array}{l}\text { Gnant } \\
\text { (ABCSG12) }\end{array}$ & 2009 & $\begin{array}{l}\text { Zoledronic acid } \\
\text { No treatment }\end{array}$ & $4 \mathrm{mg}$ IV every 6 months & 3 & $\begin{array}{l}899 \\
904\end{array}$ & 47.8 \\
\hline $\begin{array}{l}\text { Shapiro } \\
\text { (CALGB) }\end{array}$ & 2011 & $\begin{array}{l}\text { Zoledronic acid } \\
\text { No treatment }\end{array}$ & 4 mg IV every 3 months & NA & $\begin{array}{l}70 \\
80\end{array}$ & 12 \\
\hline Hershman & 2008 & $\begin{array}{l}\text { Zoledronic acid } \\
\text { Placebo }\end{array}$ & $4 \mathrm{mg}$ IV every 3 months & 1 & $\begin{array}{l}50 \\
53\end{array}$ & 12 \\
\hline $\begin{array}{l}\text { Coleman } \\
\text { (AZURE) }\end{array}$ & 2011 & $\begin{array}{l}\text { Zoledronic acid } \\
\text { No treatment }\end{array}$ & $\begin{array}{l}4 \mathrm{mg} \text { IV monthly for } 6 \text { months, then every } 3 \text { months for } 8 \text { doses } \\
\text { and then every } 6 \text { months for } 5 \text { doses }\end{array}$ & 5 & $\begin{array}{l}1665 \\
1675\end{array}$ & 6 \\
\hline $\begin{array}{l}\text { Brufsky (Z- } \\
\text { FAST) }\end{array}$ & 2009 & $\begin{array}{l}\text { Upfront } \\
\text { zoledronic acid } \\
\text { Delayed } \\
\text { zoledronci acid }\end{array}$ & 4 mg IV every 6 months & 5 & $\begin{array}{l}300 \\
300\end{array}$ & 36 \\
\hline $\begin{array}{l}\text { Eidtmann } \\
\text { (ZO-FAST) }\end{array}$ & 2010 & $\begin{array}{l}\text { Upfront } \\
\text { zoledronic acid } \\
\text { Delayed } \\
\text { zoledronci acid }\end{array}$ & 4 mg IV every 6 months & 5 & $\begin{array}{l}524 \\
536\end{array}$ & 36 \\
\hline $\begin{array}{l}\text { Hines } \\
\text { (N03CC) }\end{array}$ & 2009 & $\begin{array}{l}\text { Upfront } \\
\text { zoledronic acid } \\
\text { Delayed } \\
\text { zoledronci acid }\end{array}$ & 4 mg IV every 6 months & 5 & $\begin{array}{l}267 \\
274\end{array}$ & 12 \\
\hline
\end{tabular}

yr, year; mo, months; IV, intravenous; NA, not available

1.376, $P=0.193$ for heterogeneity) (Figure 2). However, there was no significantly different risk of muscle pain between the two groups (RR: 1.198, 95\% CI: 0.901-1.594, $P=0.366$ for heterogeneity).

Funnel plot and Egger's test were performed to access the publication bias of the four studies. No significant publication bias $(P>0.05)$ existed (data not shown).

\section{Upfront versus delayed-start ZOL}

The main results were also showed in Table 2. Arthralgia occurred in $12.7 \%-42.2 \%$ patients treated with upfront ZOL and in 11.3\%-40.7\% patients with delayed ZOL. There was no significantly different risk of arthralgia between the two groups (RR: 1.022, 95\% CI: 0.932$1.120, P=0.850$ for heterogeneity). The similar results were observed about muscle pain between the two groups (RR: 1.071, 95\% CI: 0.942-1.217, $P=0.422$ for heterogeneity). The rates of muscle pain were $6.4 \%$ $16.3 \%$ and $5.1 \%-12.1 \%$ in upfront group and delayed group, respectively. Bone pain caused by ZOL was reported in Z-FAST and ZO-FAST trials. The rate of bone pain in upfront group (119/824) was significantly higher than that in delayed group (74/836) (RR: 1.284, 95\% CI: $1.135-1.453, P=0.460$ for heterogeneity) (Figure 3 ).

Since only three trials were included in this analysis of musculoskeletal disorders between upfront and delayed ZOL groups, publication bias was not accessed.

\section{Discussion}

Previous randomized clinical trials showed that musculoskeletal disorders occurred in a high rate of patients treated with ZOL. This meta-analysis suggested that patients treated with ZOL had a statistically significant higher risk of arthralgia and bone pain compared to patients without ZOL treatment. Furthermore, patients treated with upfront ZOL had a significant higher risk of bone pain than patients with delayed ZOL.

Although ZOL can bypass the potential disadvantages of the oral route used by other bisphosphonates, it may cause more musculoskeletal disorders than other bisphosphonates [30-32]. A high rate of musculoskeletal disorders occurred in patients treated with ZOL. Patients treated with ZOL had a statistically significant

Table 2 Summary RRs and $95 \% \mathrm{CI}$

\begin{tabular}{|c|c|c|c|c|c|c|}
\hline \multirow[t]{2}{*}{ Complications } & \multicolumn{3}{|c|}{ ZOL vs no ZOL } & \multicolumn{3}{|c|}{ Upfront ZOL vs delayed ZOL } \\
\hline & RR $(95 \% \mathrm{Cl})$ & $P^{\star}$ & Number of studies & $\mathrm{RR}(95 \% \mathrm{Cl})$ & $P^{\star}$ & Number of studies \\
\hline Arthralgia & $1.162(1.096-1.232)^{\#}$ & 0.466 & 4 & $1.022(0.932-1.120)$ & 0.850 & 3 \\
\hline Bone pain & $1.257(1.149-1.376)$ & 0.193 & 2 & $1.284(1.135-1.453)$ & 0.460 & 2 \\
\hline Muscle pain & 1.198 (0.901-1.594) & 0.366 & 2 & $1.071(0.942-1.217)$ & 0.422 & 3 \\
\hline
\end{tabular}

$\mathrm{RR}$, risk ratio; $\mathrm{Cl}$, confidence interval; $\mathrm{ZOL}$, zoledronic acid;

${ }^{*} P$ value for between-study heterogeneity; \#the number in AZURE trial included the number of arthralgia and muscle pain. 

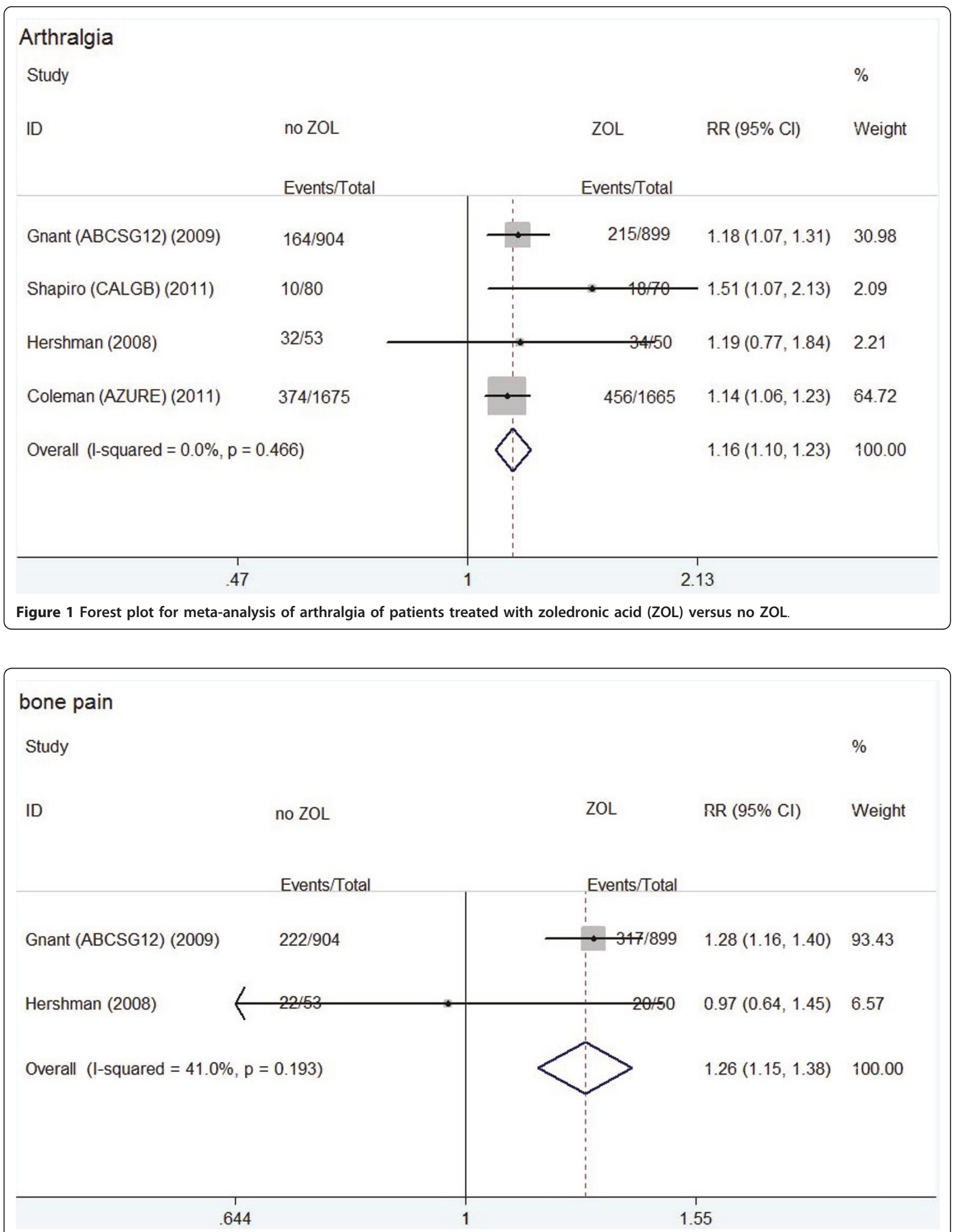

Figure 2 Forest plot for meta-analysis of bone pain of patients treated with zoledronic acid (ZOL) versus no ZOL. 


\section{Bone pain}

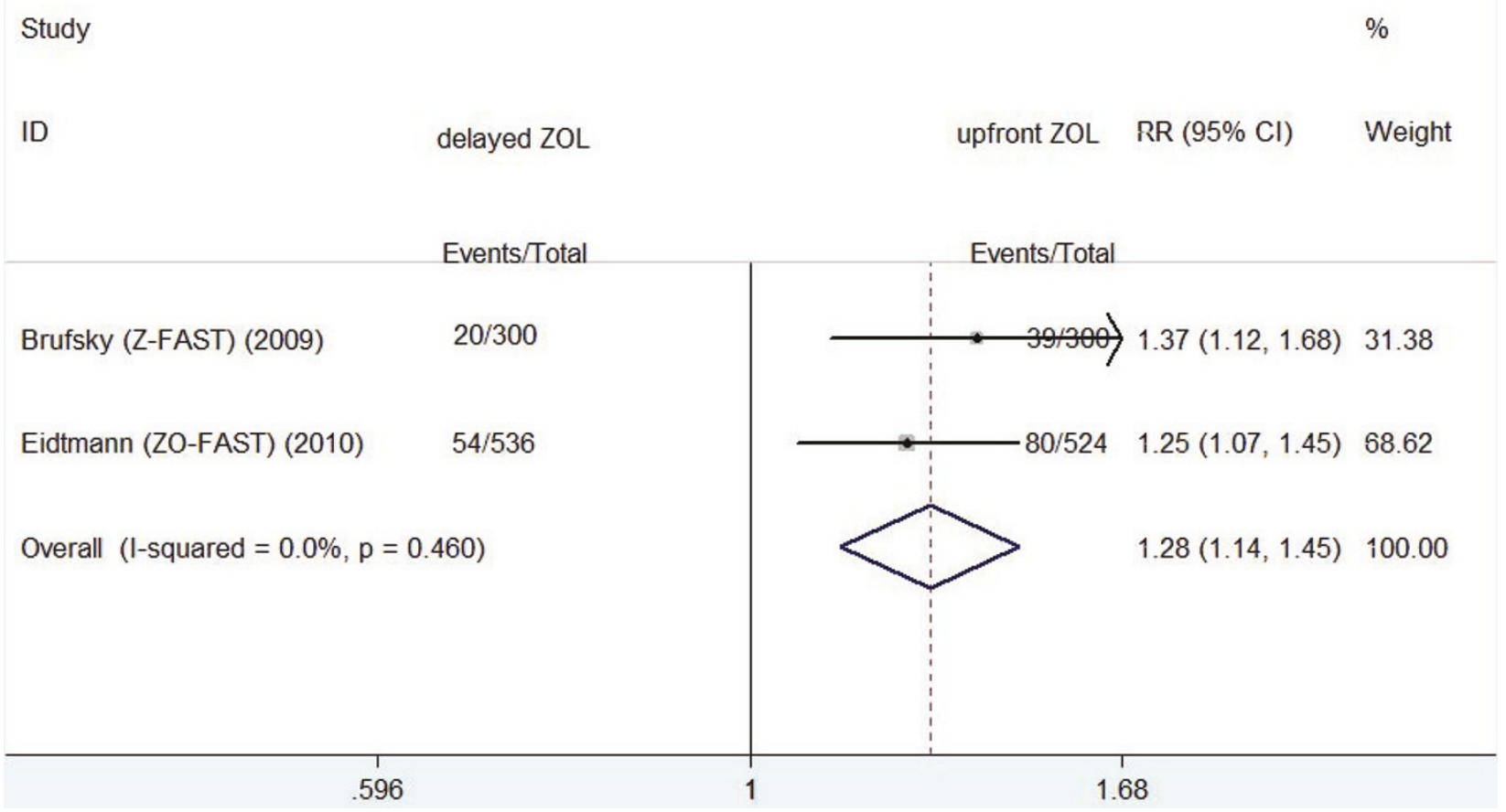

Figure 3 Forest plot for meta-analysis of bone pain of patients treated with upfront zoledronic acid (ZOL) versus delayed ZOL.

higher risk of arthralgia and bone pain than patients without ZOL treatment. These adverse effects bring anxiety to patients and may threaten patients' life quality in some conditions. These adverse effects generally resolve within 48 hours and respond well to nonsteroidal anti-inflammatory drugs [33]. Of these patients, some suffered serious musculoskeletal disorders from ZOL treatment, which exist longer and respond worse to anti-inflammatory drugs. Sometimes, serious musculoskeletal disorders cause treatment withdrawal. Although most musculoskeletal disorders will disappear spontaneously, we should take more attentions to patients treated with ZOL. The dose, frequency, and speed of infusion are all important determinants of these adverse effects [33]. When patients with high risk of osteoporosis suffered serious musculoskeletal disorders from ZOL, the risk-reducing measures should be considered. These measures included reducing the dose, slowing the infusion rate and prolonging the interval between infusions. When the patients can not tolerate these adverse effects, other oral bisphosphonates should be considered [33]. When ZOL was administrated to patients with low risk of osteoporosis, little benefit but additional musculoskeletal disorders would be brought to these patients.

Three randomized clinical trials $[12,18,19]$ were conducted to compare upfront ZOL with delayed ZOL for prevention of bone loss in postmenopausal women. These studies suggested that upfront ZOL was more effective in preserving bone mineral density than delayed ZOL, but no significant difference in fracture rate was observed. The UK Expert Group [20] suggested that patients with low risk of osteoporosis did not need a special treatment, while patients with high risk should be treated with bisphosphonates. Our results suggested more musculoskeletal disorders were observed in patients treated with upfront ZOL. Since not all patients need upfront ZOL treatment, delayed ZOL may be considered preferentially in some conditions. In addition, although ZO-FAST trial showed that upfront ZOL led to improved DFS, further randomized trials are required to investigate the survival and adverse effects between upfront $\mathrm{ZOL}$ and delayed ZOL.

Several limitations of this meta-analysis should be considered when interpreting these results. First, of these seven studies, most subjects were Caucasians, while seldom Asians were included. Second, the present results were based on unadjusted RRs. More precise estimation may be adjusted by other potential covariates. Third, due to lack of data on musculoskeletal disorders, three trials were excluded. Since these studies were with small sample size, they were unlikely to change significantly our results. 


\section{Conclusions}

This meta-analysis strongly suggested that patients treated with ZOL had a statistically significant higher risk of arthralgia and bone pain than those without ZOL treatment. Furthermore, patients treated with upfront ZOL had a significantly higher risk of bone pain than patients with delayed ZOL. More attentions should be paid to patients with musculoskeletal disorders. For patients with low risk of osteoporosis, immediate ZOL may be not needed due to additional adverse effects in some conditions. Or it can be stopped after the occurrence of these adverse events. Further randomized clinical trials with large sample size should be taken to evaluate the side effects of ZOL, especially for musculoskeletal disorders.

\section{List of abbreviations}

Al: aromatase inhibitor; $\mathrm{Cl}$ : confidence interval; DFS: disease-free survival; OS: overall survival; RR: risk ratio; ZOL: zoledronic acid.

\section{Acknowledgements}

We are grateful to Dr. Jifu Wei (Clinical Experiment Center, the First Affiliated Hospital with Nanjing Medical University) for critical discussion in our study. This work was supported in part by Wu Jie-Ping Foundation (320.670010009), the National Natural Science Foundation of China (81071753), the Six Kinds of Outstanding Talent Foundation of Jiangsu Province (To Wei He), the Science and Education for Health Foundation of Jiangsu Province (RC2007054), the Natural Science Foundation of Jiangsu Province (BK2008476, BK2009438 and BK2010581), the Program for Development of Innovative Research Team in the First Affiliated Hospital of NJMU (IRT-008), and A project Funded by the Priority Academic Program Development of Jiangsu higher Education Institutions (PAPD).

\section{Author details}

'Department of Breast Surgery, The First Affiliated Hospital with Nanjing Medical University, 300 Guangzhou Road, 210029 Nanjing, China. 2Department of Gerontology, Jiangsu Province Official Hospital, 65 Jiangsu Road, 210009 Nanjing, China. ${ }^{3}$ Department of Endocrinology and Metabolism, The First Affiliated Hospital with Nanjing Medical University, 300 Guangzhou Road, 210029 Nanjing, China.

\section{Authors' contributions}

$\mathrm{WH}$ has contributed to the conception and design of the study, the analysis and interpretation of data, the revision of the article as well as final approval of the version to be submitted. WBZ and XAL participated in the design of the study, performed the statistical analysis, searched and selected the trials, drafted and revised the article. PLZ drafted and revised the article. TY participated in the design of the study and helped to revise the article. All authors read and approved the final version of the manuscript.

\section{Conflict of interest}

The authors declare that they have no competing interests.

Received: 23 June 2011 Accepted: 4 August 2011

Published: 4 August 2011

\section{References}

1. Elmore JG, Armstrong K, Lehman CD, Fletcher SW: Screening for breast cancer. JAMA 2005, 293:1245-1256.

2. Early Breast Cancer Trialists' Collaborative Group (EBCTCG): Effects of chemotherapy and hormonal therapy for early breast cancer on recurrence and 15-year survival: an overview of the randomised trials. Lancet 2005, 365:1687-1717.
3. Forbes JF, Cuzick J, Buzdar A, Howell A, Tobias JS, Baum M: Effect of anastrozole and tamoxifen as adjuvant treatment for early-stage breast cancer: 100-month analysis of the ATAC trial. Lancet Oncol 2008, 9:45-53.

4. Coates AS, Keshaviah A, Thurlimann B, Mouridsen H, Mauriac L, Forbes JF, Paridaens R, Castiglione-Gertsch M, Gelber RD, Colleoni M, Lang I, Del Mastro L, Smith I, Chirgwin J, Nogaret JM, Pienkowski T, Wardley A, Jakobsen EH, Price KN, Goldhirsch A: Five years of letrozole compared with tamoxifen as initial adjuvant therapy for postmenopausal women with endocrine-responsive early breast cancer: update of study BIG 1-98. J Clin Oncol 2007, 25:486-492.

5. Di Cosimo S, Alimonti A, Ferretti G, Sperduti I, Carlini P, Papaldo P, Fabi A, Gelibter A, Ciccarese M, Giannarelli D, Mandalà M, Milella M, Ruggeri EM, Cognetti F: Incidence of chemotherapy-induced amenorrhea depending on the timing of treatment by menstrual cycle phase in women with early breast cancer. Ann Oncol 2004, 15:1065-1071.

6. Zhou WB, Yin H, Liu XA, Zha XM, Chen L, Dai JC, Tao AD, Ma JJ, Ling LJ, Wang S: Incidence of chemotherapy-induced amenorrhea associated with epirubicin, docetaxel and navelbine in younger breast cancer patients. BMC Cancer 2010, 10:281.

7. Fuleihan Gel H, Salamoun M, Mourad YA, Chehal A, Salem Z, Mahfoud Z, Shamseddine A: Pamidronate in the prevention of chemotherapyinduced bone loss in premenopausal women with breast cancer: a randomized controlled trial. J Clin Endocrinol Metab 2005, 90:3209-3214.

8. Shapiro CL, Manola J, Leboff M: Ovarian failure after adjuvant chemotherapy is associated with rapid bone loss in women with earlystage breast cancer. J Clin Oncol 2001, 19:3306-3311.

9. Simpson ER, Dowsett M: Aromatase and its inhibitors: significance for breast cancer therapy. Recent Prog Horm Res 2002, 57:317-338.

10. Jansen JP, Bergman GJ, Huels J, Olson M: The efficacy of bisphosphonates in the prevention of vertebral, hip, and nonvertebral-nonhip fractures in osteoporosis: a network meta-analysis. Semin Arthritis Rheum 2011, 40:275-284, e271-272.

11. Mauri D, Valachis A, Polyzos NP, Tsali L, Mavroudis D, Georgoulias V, Casazza G: Does adjuvant bisphosphonate in early breast cancer modify the natural course of the disease? A meta-analysis of randomized controlled trials. J Natl Compr Canc Netw 2010, 8:279-286.

12. Hines SL, Mincey B, Dentchev T, Sloan JA, Perez EA, Johnson DB, Schaefer PL, Alberts S, Liu H, Kahanic S, Mazurczak MA, Nikcevich DA, Loprinzi CL: Immediate versus delayed zoledronic acid for prevention of bone loss in postmenopausal women with breast cancer starting letrozole after tamoxifen-N03CC. Breast Cancer Res Treat 2009, 117:603-609.

13. Mauri D, Valachis A, Polyzos IP, Polyzos NP, Kamposioras K, Pesce LL: Osteonecrosis of the jaw and use of bisphosphonates in adjuvant breast cancer treatment: a meta-analysis. Breast Cancer Res Treat 2009, 116:433-439.

14. Gnant M, Mlineritsch B, Schippinger W, Luschin-Ebengreuth G, Pöstlberger S, Menzel C, Jakesz R, Seifert M, Hubalek M, Bjelic-Radisic V, Samonigg H, Tausch C, Eidtmann H, Steger G, Kwasny W, Dubsky P, Fridrik M, Fitzal F, Stierer M, Rücklinger E, Greil R, ABCSG-12 Trial Investigators, Marth C: Endocrine therapy plus zoledronic acid in premenopausal breast cancer. N Engl J Med 2009, 360:679-691.

15. Shapiro CL, Halabi S, Hars V, Archer L, Weckstein D, Kirshner J, Sikov W, Winer E, Burstein HJ, Hudis C, Isaacs C, Schilsky R, Paskett E: Zoledronic acid preserves bone mineral density in premenopausal women who develop ovarian failure due to adjuvant chemotherapy: final results from CALGB trial 79809. Eur J Cancer 2011, 47:683-689.

16. Hershman DL, McMahon DJ, Crew KD, Cremers S, Irani D, Cucchiara G, Brafman L, Shane E: Zoledronic acid prevents bone loss in premenopausal women undergoing adjuvant chemotherapy for earlystage breast cancer. J Clin Oncol 2008, 26:4739-4745.

17. Coleman R, Woodward E, Brown J, Cameron D, Bell R, Dodwell D, Keane M, Gil M, Davies C, Burkinshaw R, Houston SJ, Grieve RJ, Barrett-Lee PJ, Thorpe H: Safety of zoledronic acid and incidence of osteonecrosis of the jaw (ONJ) during adjuvant therapy in a randomised phase III trial (AZURE: BIG 01-04) for women with stage II/III breast cancer. Breast Cancer Res Treat 2011, 127:429-438.

18. Brufsky AM, Bosserman LD, Caradonna RR, Haley BB, Jones CM, Moore HC Jin L, Warsi GM, Ericson SG, Perez EA: Zoledronic acid effectively prevents aromatase inhibitor-associated bone loss in postmenopausal women 
with early breast cancer receiving adjuvant letrozole: Z-FAST study 36month follow-up results. Clin Breast Cancer 2009, 9:77-85.

19. Eidtmann H, de Boer R, Bundred N, Llombart-Cussac A, Davidson N, Neven P, von Minckwitz G, Miller J, Schenk N, Coleman R: Efficacy of zoledronic acid in postmenopausal women with early breast cancer receiving adjuvant letrozole: 36 -month results of the ZO-FAST Study. Ann Oncol 2010, 21:2188-2194.

20. Reid DM: Prevention of osteoporosis after breast cancer. Maturitas 2009, 64:4-8.

21. Zhou WB, Xue DQ, Liu XA, Ding Q, Wang S: The influence of family history and histological stratification on breast cancer risk in women with benign breast disease: a meta-analysis. J Cancer Res Clin Oncol 2011, 137:1053-1060.

22. Zhou WB, Ding Q, Chen L, Liu XA, Wang S: Toremifene is an effective and safe alternative to tamoxifen in adjuvant endocrine therapy for breast cancer: results of four randomized trials. Breast Cancer Res Treat 2011, 128:625-631

23. Liu X, Wang Z, Yu J, Lei G, Wang S: Three polymorphisms in interleukin1 beta gene and risk for breast cancer: a meta-analysis. Breast Cancer Res Treat 2010, 124:821-825.

24. Lau J, loannidis JP, Schmid CH: Quantitative synthesis in systematic reviews. Ann Intern Med 1997, 127:820-826.

25. Mantel N, Haenszel W: Statistical aspects of the analysis of data from retrospective studies of disease. J Natl Cancer Inst 1959, 22:719-748.

26. DerSimonian R, Laird N: Meta-analysis in clinical trials. Control Clin Trials 1986, 7:177-188.

27. Leal T, Tevaarwerk A, Love R, Stewart J, Binkley N, Eickhoff J, Parrot B, Mulkerin D: Randomized trial of adjuvant zoledronic acid in postmenopausal women with high-risk breast cancer. Clin Breast Cancer 2010, 10:471-476.

28. Swenson KK, Nissen MJ, Anderson E, Shapiro A, Schousboe J, Leach J: Effects of exercise vs bisphosphonates on bone mineral density in breast cancer patients receiving chemotherapy. J Support Oncol 2009, 7:101-107.

29. Kim JE, Ahn JH, Jung KH, Kim SB, Kim HJ, Lee KS, Ro JS, Park YH, Ahn JS, Im YH, Im SA, Lee MH, Kim SY: Zoledronic acid prevents bone loss in premenopausal women with early breast cancer undergoing adjuvant chemotherapy: a phase III trial of the Korean Cancer Study Group (KCSG-BR06-01). Breast Cancer Res Treat 2011, 125:99-106

30. Van Poznak C, Hannon RA, Mackey JR, Campone M, Apffelstaedt JP, Clack G, Barlow D, Makris A, Eastell R: Prevention of aromatase inhibitor-induced bone loss using risedronate: the SABRE trial. J Clin Oncol 2010, 28:967-975.

31. Hines SL, Mincey BA, Sloan JA, Thomas SP, Chottiner E, Loprinzi CL, Carlson MD, Atherton PJ, Salim M, Perez EA: Phase III randomized, placebo-controlled, double-blind trial of risedronate for the prevention of bone loss in premenopausal women undergoing chemotherapy for primary breast cancer. J Clin Oncol 2009, 27:1047-1053.

32. Markopoulos C, Tzoracoleftherakis E, Polychronis A, Venizelos B, Dafni U, Xepapadakis G, Papadiamantis J, Zobolas V, Misitzis J, Kalogerakos K, Sarantopoulou A, Siasos N, Koukouras D, Antonopoulou Z, Lazarou S, Gogas H: Management of anastrozole-induced bone loss in breast cancer patients with oral risedronate: results from the ARBI prospective clinical trial. Breast Cancer Res 2010, 12:R24.

33. Diel IJ, Bergner R, Grotz KA: Adverse effects of bisphosphonates: current issues. J Support Oncol 2007, 5:475-482.

doi:10.1186/1756-9966-30-72

Cite this article as: Zhou et al: Innegligible musculoskeletal disorders caused by zoledronic acid in adjuvant breast cancer treatment: a metaanalysis. Journal of Experimental \& Clinical Cancer Research 2011 30:72.

\section{Submit your next manuscript to BioMed Central and take full advantage of:}

- Convenient online submission

- Thorough peer review

- No space constraints or color figure charges

- Immediate publication on acceptance

- Inclusion in PubMed, CAS, Scopus and Google Scholar

- Research which is freely available for redistribution 